\title{
Report of the Executive Secretary-Treasurer November 1987
}

This past year the Secretariat of MESA has been transferred from New York University to the University of Arizona. This took place in the summer, and much time and effort has been spent in getting MESA operational in Tucson. This report will, of necessity, concentrate on the operations and activities in Tucson.

The central office of MESA is in the Franklin Building at the University of Arizona, housed with the Department of Oriental Studies (where the Near East Center is also located). We have a large office which is able to hold not only the files and records of the Association, but also a substantial number of the back issues of the Bulletin and our other publications. The office of the Executive Secretary-Treasurer is next to the MESA Secretariat, with a phone system that interconnects with the MESA office to facilitate intercommunication between the Executive Secretary and the office.

A major goal in Tucson is to have an efficient office operation. Routine correspondence on membership, publications, and other inquiries is handled promptly - usually the same day received. The records are being reorganized for better use. Membership files are being streamlined and brought up to date. A new set of accounting books and records is being established, placing MESA accounts on the accrual system.

The first major publications of the Tucson MESA office have been the annual ballot for the 1981 elections and the Fall Newsletter. A number of changes in the ballot and the Newsletter have been instituted; we hope that the membership will benefit from the changes in the formats. In the future, the information on candidates may be included in the Fall Newsletter - a measure which should save the membership considerable printing costs.

In order for the Newsletter to be informative and timely, please keep in mind the deadlines for submitting materials. Please keep sending us your material. Right now the Newsletter is being published three times a year, but we hope to publish it more frequently if our finances improve.

The Directory of Undergraduate and Graduate Programs and Courses in Middle East Studies in the United States, Canada and Abroad is now being actively pursued. New forms had to be sent out to the institutions; the majority have now been returned to the Secretariat. The Directory should be ready for publication by the beginning of next year. We plan to adhere to the two-year cycle after this Directory. For the next issue, we hope to have a more comprehensive survey of foreign programs, and to be able to include the section on Middle East library collections once again.

Cambridge University Press (CUP) continues to maintain the membership lists, providing the Secretariat with monthly listings of members. Unfortunately, the potential of the computer printout has not been fully utilized, and CUP is now in the process of putting into their system some of our requests. These include such basic requirements as totals of each membership category and length of membership, as well as a category designating the discipline of the members. This last category would make part of the compilation of the Roster much easier - and less expensive.

CUP recently undertook a major advertising campaign for the $I n-$ 
ternational Journal of Middle East Studies. A number of new members have resulted from this endeavor - as well as from direct inquiries to MESA. In September of 1980, the member ship stood at 1,163, rose to 1,235 in March of 1981 , and is up to about 1,300 today.

Membership dues for 1982 will be $\$ 40$ for Full and Associate Members; $\$ 18$ for Student and Retired Members. Joint membership will also be available at a cost of an additional $\$ 10 \quad$ ( $\$ 50$ for Full and Associate Members; $\$ 28$ for Student and Retired Members). Institutional dues will be $\$ 67.50$.

At our request, CUP has now instituted an overseas airmail service from New York. This will cost $\$ 35$ above the regular dues.

CUP continues to print the Bulletin, two issues a year. The editorship has remained in the able hands of Prof. Jere Bacharach and his staff at the University of Washington, who continue to prepare the camera-ready copy. MESA has taken over the subsidy of $\$ 2,500$ per year, previously provided by the University of Washington.

The editorship of IJMES has remained in the capable hands of Prof. A. Marsot and her staff at UCLA. A number of new people have been added to the Board of Editors of IJMES. They are: Ali Dessouki, Andre Raymond, Robert Mabro, and Ergun O zbudun. The book reviews will now be handled out of UCLA, with the work being shared among a number of editors. They are: Michael Suleiman for Social Science; Peter von Sivers for History and Islamic Studies; and Mona Mikhail for Literature. The term of office will be for five years (1982-1986) .

The National Endowment for the Humanities has awarded MESA a grant of $\$ 100,000$ to continue the Near East National Union List Project at the Library of Congress (this will be from February 1982 to January 1985). Also, within the provisions of the grant is an additional $\$ 240,080$, on the condition that matching funds of one-half this amount $(\$ 120,040)$ are found by January 31,1984 (with all matching NEH money being subject to the availability of sufficient funds by NEH).

The Gulf Oil Foundation has made a generous contribution of $\$ 1,000$ toward our general operations, and Esso Middle East (Exxon) has generously supplied us with $\$ 2,500$ toward the publishing of the forthcoming Directory. The Near East Center of the University of Arizona has provided MESA with a $\$ 500$ grant to help pay the staff working on the Directory.

We wish to thank all these institutions, corporations and individuals for their support.

\author{
Respectfully submitted, \\ Michael E. Bonine \\ Executive Secretary-Treasurer
}

